8. Saidha S, Sotirchos ES, Ibrahim MA, et al. Microcystic macular oedema, thickness of the inner nuclear layer of the retina, and disease characteristics in multiple sclerosis: a retrospective study. Lancet Neurol 2012;11:963-972.

\section{OLFACTORY DYSFUNCTION IN PATIENTS WITH IDIOPATHIC INTRACRANIAL HYPERTENSION}

Kah Fang Khoo, Bayan Lepas, Malaysia: This interesting pilot study ${ }^{1}$ provides new evidence that patients with idiopathic intracranial hypertension (IIH) may have olfactory dysfunction. This feature is added to more conventional symptoms like headache, nausea, vomiting, and double vision. This is helpful as the Sniffin' Sticks procedure is less invasive than lumbar puncture and less expensive than MRI. Schmidt et al. ${ }^{2}$ demonstrated reduction of olfactory bulb volume using MRI. A future study should include reduction of olfactory function as one of the minor criteria for diagnosing IIH and rule out space-occupying lesions and high intracranial pressure.

Author Response: Hagen Kunte, Felix Schmidt, Jan Hoffmann, Lutz Harms, Golo Kronenberg, Berlin: We appreciate the suggestion that an assessment of olfactory function by the extended Sniffin' Sticks procedure may be helpful in the diagnosis and follow-up of IIH. The prevalence of absolute hyposmia in patients with a recent first diagnosis of IIH or patients with a clinically significant worsening of IIH within the last 3 months reached $80 \%$ in our sample. ${ }^{1}$ We agree that the presence of olfactory dysfunction should be considered as one of the minor criteria for diagnosing IIH. However, other potential causes of reduced olfactory function must first be ruled out. In contrast, olfactory testing is less appropriate as a follow-up measure in patients with diagnosed IIH because olfactory function typically trails changes in intracranial pressure (ICP) by several weeks. Emerging evidence suggests that 3D spectral-domain optical coherence tomography of the optic nerve head might be used to noninvasively monitor IIH and possibly other disorders with increased ICP. ${ }^{3}$

(C) 2014 American Academy of Neurology

1. Kunte H, Schmidt F, Kronenberg G, et al. Olfactory dysfunction in patients with idiopathic intracranial hypertension. Neurology 2013;81:379-382.

2. Schmidt C, Wiener E, Hoffmann J, et al. Structural olfactory nerve changes in patients suffering from idiopathic intracranial hypertension. PLoS One 2012;7:e35221.

3. Kaufhold F, Kadas EM, Schmidt C, et al. Optic nerve head quantification in idiopathic intracranial hypertension by spectral domain OCT. PLoS One 2012;7:e36965.

\title{
CORRECTION
}

Teaching NeuroImages: Dyspnea as a presenting manifestation of amyloid myopathy

In regard to the article "Teaching NeuroImages: Dyspnea as a presenting manifestation of amyloid myopathy" by P.S. Ghosh et al. (Neurology ${ }^{\circledR}$ 2013;81:e184), there is an error in the cover image text found at the end of the Table of Contents. It should have read: "Trichrome stain of a deltoid muscle showing a necrotic muscle fiber in a patient with amyloid myopathy." The authors regret the error. 


\section{Neurology}

\section{Olfactory dysfunction in patients with idiopathic intracranial hypertension}

Kah Fang Khoo, Hagen Kunte, Felix Schmidt, et al.

Neurology 2014;82;189

DOI 10.1212/01.wnl.0000442872.80558.6c

\section{This information is current as of January 13, 2014}

\section{Updated Information \&} Services

References

Permissions \& Licensing

Reprints including high resolution figures, can be found at: http://n.neurology.org/content/82/2/189.1.full

This article cites 3 articles, 1 of which you can access for free at: http://n.neurology.org/content/82/2/189.1.full\#ref-list-1

Information about reproducing this article in parts (figures,tables) or in its entirety can be found online at:

http://www.neurology.org/about/about_the_journal\#permissions

Information about ordering reprints can be found online:

http://n.neurology.org/subscribers/advertise

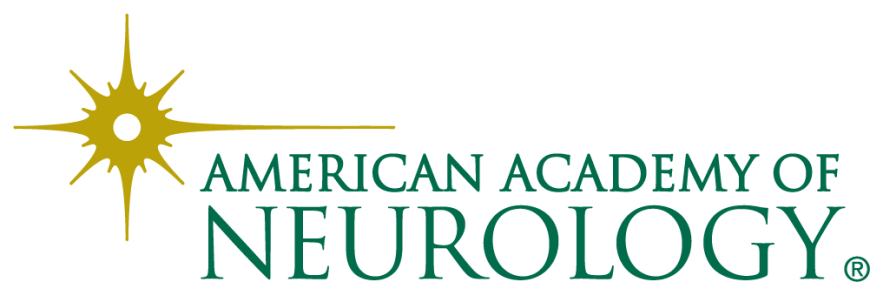

